\title{
A CASE OF STRICTURE OF THE RECTUM,
}

WHEREIN AN ARTIFICIAL ANUS WAS SUCCESSFULLY ESTABLISHED

IN THE LEFT LUMBAR REGION.

BX

J. WILSON CROKER PENNELL, M.B. (LOND.), M.R.C.S. LICENTIATE OF THE FACULTY OF MEDICINE OF RIO DE JANEIRO, FORMERLY LECTURER ON ANATOMY AND PHYSIOLOGY AT THE WESTMINSTER HOSPITAL, SCHOOL OF MEDICINE.

COMMUNICATED BY

BENJAMIN PHILLIPS, F.R.S.

Received April 9th.-Read May 14th, 1850.

Mr. G. G., aged about 50, director of a college within five miles of Rio de Janeiro, suffered six years ago from piles and fistula, for the latter of which he underwent an operation.

About five years ago, he himself discovered, that he had a stricture of the rectum. Upon examination, his discovery proved to be true. This stricture was treated by bougies, and upon several occasions by free division of the stricture by the knife, but without more than temporary benefit. When I first saw him, two years ago, his suffering had increased, and the stricture was found to be very narrow, with difficulty admitting the point of the finger. The neighbourhood of the anus bore severe traces of the knife. He relates, and the medical man who' operated upon him confirms his statement, that when the stricture was divided, it snapped with a noise resembling that produced by the division of a tendon when cut upon the stretch. To the finger the gut feels as hard as cartilage.

It was found impossible to continue the use of instruments either for the purpose of dilatation, or for keeping the stricture 
open after division, in consequence of the extreme suffering and constitutional irritation which ensued.

Being thus far acquainted with the history of the case, when I took charge of it, I determined to limit my efforts to the alleviation of his suffering, and to avoid all meddling with the gut, as he could not bear bougies, and after each division the stricture became worse. At times I thought of operating for the formation of artificial anus ; but his shattered system, and the damaged condition of his organs, generally dispelled the idea. Thus the chest was found to be duller than natural upon percussion at certain points, and here the respiratory murmur was almost absent, and replaced by a coarse loud respiration, expiration being considerably louder than inspiration. The heart was very easily excited to violent palpitation, and the liver had several times been affected by serious inflammatory disease, and frequently was still the seat of great distress and pain; nor had the kidneys escaped, having at times suffered severely.

Sixteen months ago his suffering having increased, a consultation was held, the result of which was a determination to continue the same palliative treatment.

I then proposed an operation as a last resource, and advised that the descending colon should be opened in the left lumbar region where it is uncovered by peritoneum, and that a permanent artificial anus should be formed ; but this proposition received no countenance.

Shortly, in consequence of violent and repeated straining at stool, the bowels ulcerated, and the fæces formed a false passage into the urethra and bladder; so that from this time nearly all the fæces passed through the penis. He had also a narrow stricture, no surgeon having been able to introduce an instrument into the bladder for eighteen years. His sufferings now were much increased. Being able to pass so little at a time, the calls to stool became very frequent, and the matters passed were chiefly thin and bilious, and so acrid, that they quickly inflamed the urethra At times, bits of bone, which he had unknowingly swallowed, caught in the mucous membrane of the urethra, and obstructing all behind, 
occasioned great injury to the membrane and torture to the patient. Frequently they remained several days in the passage, giving rise to increasing distress. The bladder became daily filled with gas, which produced a sensation as if it were about to burst, to the no small suffering of the patient, who could get no relief till, upon evacuating his urine, both escaped together with a loud noise. At times particles of fæces were driven to a considerable distance by the liberated air.

The constant irritation at the seat of disease superinduced attacks of inflammation in the different organs holding nervous communication with it. First the testicles inflamed, and from the necessity of avoiding violent remedies to subdue the disease, they partially suppurated. Next followed, conjointly, inflammation of the liver and kidneys, by which he was brought into a state of such serious exhaustion, that there seemed no chance of life being much extended. Moreover he slowly rallied, but was left in a worse condition than before; there was more urgent suffering, and in addition hectic fever came on every evening, so that his system at last was evidently giving way under such protracted suffering and such an accumulation of disease. Seeing that his death was not distant, unless art could interpose a saving arm, I determined, without any further consultation, to open the descending colon, if, upon explaining the difficulties and dangers of the operation, the patient should desire it; which he most urgently did, and fixed upon the following Sunday, November 4th, 1849 , for its performance.

Operation.-Present, Dr. Malet and Dr. Curtis. Dr. Persiani and Dr. Marinho had promised to attend, but were unavoidably prevented. The former, however, saw the patient five days after the operation. Dr. Curtis having administered chloroform, and declared the patient to be fully under its in. fluence, I commenced the operation by an incision beginning immediately underneath the twelfth rib on the left side, and continued down to the crista iliæ; this incision corresponded to the outer margin of the quadratus lumborum muscle. I then divided the skin, fat, and superficial fascia. By a few

xxxiII. 
strokes of the knife, I next divided a fascia and some scattered muscular fibres belonging to the transversalis and oblique abdominal muscles. A dense fascia nọw presented itself, upon dividing which the outer edge of the quadratus lumborum was clearly seen. Another and another exceedingly dense fascia (the transversalis) was now carefully opened, and divided upon a director upwards and downwards, to the full extent of the external incision. Some loose cellular tissue, forming the anterior layer of the transversalis fascia, having been next cut through without a director, a large quantity of fat was exposed. This having been very carefully removed, layer after layer, the posterior surface of the intestine was at length reached. Having satisfied myself that it was really intestine, I carefully opened it with a scalpel and forceps, to the extent of at least an inch and a half. Four sutures were now applied to the margins of the open gut to secure them to the skin,-one at the upper extremity of the incision, one below, and one at each side, so that the bowel was made to gape, and a spectator (without touching the patient) could easily see the interior of it. Only one artery required ligature.

On the following day, the pressure from within had caused the lower portion of the gut to protrude slightly between the edges of the wound, and still continues there. This was a great advantage, as it effectually prevented any wind or fæces from passing down to the lower part of the gut, and entering the strictured bowel.

The gut united in its new position by the first intention to the parts with which it had recently been brought into contact; a small quantity of pus was formed at the upper end of the wound only.

Within three days after the operation, the hectic fever ceased, although the pulse continued to beat 125 times in a minute. A fortnight after it was reduced to 100 , and it is now (seven weeks after) 78. The patient's appearance is very much improved, having acquired a considerable increase in flesh. He is entirely relieved of his sufferings, and walks about with ease. For the first three or four days, the urine passed entirely through the anus; it then began to come 
through the urethra, but mixed with a large quantity of pus, which however has been gradually diminishing, and is now scarcely anything. The urine at times has passed up the bowel and escaped at the.wound.

If the operation just described, which is that of Callisen, can be shown to be the best for the formation of artificial anus, in cases requiring it, and that when properly performed, it is attended with but little immediate danger, it will be at once conceded, that it has not been had recourse to so frequently as circumstances demanded. Amussat has established, beyond doubt, its claims as a regular operation of surgery, and is entitled to as much honour as if he had been the original proposer.

The difficulties of the operation have been very much exaggerated. I believe the intestine will always be readily found by an incision made along the outer edge of the quadratus lumborum muscle and carried straight forwards, taking especial care that the deepening of the wound incline rather internally than externally, as the intestine frequently lies somewhat concealed by the muscle. The operator must not be disconcerted by having to wade through a large quantity of fat, after dividing completely the abdominal parietes, and before reaching the intestine. This fat moves in and out of the wound with every expiration and inspiration. In the foregoing case, when the bowel was cleared of the fat covering it, it appeared of a grayish colour, loosely bulging into the bottom of the wound, flaccid, and could easily be taken hold of between the finger and thumb, imparting the feel of a double intestine, which was accordingly opened.

I much prefer the vertical to the transverse incision recommended by M. Amussat, and I think it will less frequently lead to difficulty in finding the intestine, or danger of opening the peritoneum; as by the former we are brought down directly upon the intestine, if we take care to incline our cutting rather internal than external to the outer margin of the quadratus lumborum muscle. If the subject were fat, a crucial incision would be requisite. 
As to the dangers of the operation, they are but few, and only those which are common to the most trifling wounds, viz. common and erysipelatous inflammation and deep suppuration. These occurrences probably would not often destroy life. Even in the shattered frame upon which I operated, the intestine united readily with the parts in contact with which it had recently been brought. Only a few drops of pus were formed. I would have recourse to this operation in every case of stricture of the rectum (not curable by the use of the bougies), which produced severe suffering to the patient, prevented him following the ordinary avocations of life, or which was beginning to destroy the health, undermine the constitution, or to set up irritation in the different organs holding nervous communication with the seat of disease, as the liver, kidneys, testicles, \&c. \&c. 